\title{
Correction to: Municipal Power and Population Decline in Japan
}

\section{Correction to:}

\section{F. Kumagai, Municipal Power and Population Decline in Japan, https://doi.org/10.1007/978-981-15-4234-3}

In the original version of the book, corrections in the following chapters have been incorporated:

In Chapter 4, Tables 4.1 and 4.3 have been updated.

In Chapter 5, Tables 5.1, 5.5 and 5.8 have been updated.

In Chapter 6, Tables 6.1 and 6.4 have been updated.

In Chapter 7, Tables 7.1 and 7.3 have been updated.

The book and the chapters have been updated with the changes.

\footnotetext{
The updated versions of these chapters can be found at https://doi.org/10.1007/978-981-15-4234-3_4 https://doi.org/10.1007/978-981-15-4234-3_5 https://doi.org/10.1007/978-981-15-4234-3_6 https://doi.org/10.1007/978-981-15-4234-3_7 